\title{
The Individual-Level Patterns Underlying the Decline of Routine Jobs
}

\section{Guido Matias Cortes}

\section{(2) OpenEdition}

1 Journals

\section{Electronic version}

URL: http://journals.openedition.org/travailemploi/8869

DOI: 10.4000/travailemploi.8869

ISSN: 1775-416X

\section{Publisher}

DARES - Ministère du Travail

\section{Printed version}

Date of publication: 1 January 2019

Number of pages: $45-66$

ISSN: 0224-4365

\section{Electronic reference}

Guido Matias Cortes, «The Individual-Level Patterns Underlying the Decline of Routine Jobs », Travail et Emploi [Online], 157 | 2019, Online since 01 January 2019, connection on 11 October 2019. URL: http://journals.openedition.org/travailemploi/8869; DOI : 10.4000/travailemploi.8869 


\title{
The Individual-Level Patterns Underlying the Decline of Routine Jobs*
}

\author{
Guido Matias Cortes ${ }^{* *}$
}

\begin{abstract}
This article reviews the findings from CORTES (2016) and CORTES, JAIMOVICH, and SIU (2017), which explore the micro-level patterns associated with the decline in middle-wage routine employment in the United States. I show that male workers who remain in routine jobs experience significantly slower long-run wage growth than those who switch to other occupations, even when compared to those who transition to lower-skill non-routine manual jobs. I also show that changes in the employment patterns of men with low levels of education and women with intermediate levels of education account for the majority of the decline in routine employment. Individuals with these demographic characteristics used to predominantly work in routine jobs. In more recent years, they have become increasingly likely to be out of work.
\end{abstract}

$\mathrm{O}$ ver recent decades, many developed countries have experienced marked declines in the fraction of the population employed in middle-skill occupations (e.g. Dustmann et al., 2009; Goos et al., 2009; Acemoglu, Autor, 2011; Goos et al, 2014; Jaimovich, SiU, 2012; Albertini et al., 2017; Goos et al., 2019). This has been linked to the declining employment in occupations that are intensive in routine tasks, i.e., occupations that focus on a relatively narrow set of job tasks that can be performed by following a well-defined set of instructions and procedures. The key insight, first put forward by AUTOR et al. (2003), is that recent technological changes have resulted in the creation of machines, computers, and other forms of capital that are particularly effective at performing tasks that are routine in nature. This new capital therefore acts as a substitute for workers in occupations that feature a high content of routine tasks. As shown by Goos and MANnING (2007) and the subsequent literature, these routine occupations tend to be in the middle of the wage distribution. Although there is a large

\footnotetext{
* I thank the Social Sciences and Humanities Research Council of Canada for financial support. This article reviews findings from my past work, and was prepared for the conference "Polarization(s) in Labor Markets" organized by the Direction de l'animation de la recherche, des études et des statistiques (DARES) and the International Labour Organization (ILO) in Paris on June 19, 2018.

** York University; gmcortes@yorku.ca.
} 
and growing literature documenting overall patterns of labor market polarization, relatively little is known about the individual-level patterns underlying these changes. The question of who has been impacted by the decline of routine employment, and how those affected have adjusted to these changes, is not only of academic interest, but is also essential in order to design appropriate public policy responses to the observed labor market changes.

In this article I review the findings from two papers that analyze the individuallevel patterns underlying the decline in routine employment in the U.S. The first, CORTES (2016), uses longitudinal data to track male workers who are initially employed in routine occupations, and explores their subsequent occupational mobility patterns and the associated short and long-term wage changes that they experience. The second, CORTES, JAIMOVICH, and SiU (2017) takes a broader view, analyzing which demographic groups account for the majority of the decline in routine employment, and how they have adjusted in terms of their employment outcomes. ${ }^{1}$

When focusing on male workers who are initially employed in routine occupations, and tracking their occupational mobility patterns over time, I find strong evidence of selection on ability among those who switch occupations. Specifically, routine workers with low ability (that is, those with relatively low wages compared to other routine workers) are more likely to switch to non-routine manual jobs, while those with high ability are more likely to switch to non-routine cognitive jobs. Interestingly, I find that workers who switch to other jobs -regardless of the direction in which they switch-experience significantly faster wage growth over long-run horizons compared to those who stay in routine jobs. ${ }^{2}$

While these results focus on individuals who were already employed in routine jobs, it is clear that many individuals who used to find employment in these types of jobs are no longer able to do so. Using cross-sectional data for the entire working-age population in the U.S. between 1979 and 2014, I show that changes among a relatively small subset of demographic groups can account for the vast majority of the decline in per capita routine employment. Specifically, the decline in routine manual employment is primarily attributable to changes among young and prime-aged men with low levels of education, while the majority of the decline in routine cognitive employment is accounted for by changes in the employment patterns of young and prime-aged women with intermediate levels of education. In addition to becoming much less likely to work in routine jobs, individuals from these groups have experienced sharp increases in the

\footnotetext{
1. While I focus here on heterogeneity across individuals, other papers in the literature have explored heterogeneity across other dimensions, such as local labor markets (e.g. AUTOR, DoRn, 2013; DAUTH, 2014; AUTOR et al., 2015) or firms (e.g PekKala Kerr et al., 2016; Böckerman et al., 2019; Cortes, Salvatori, 2019; Harrigan et al., 2016; HEYMAN, 2016).

2. A separate and rich strand of the literature studies occupational mobility and its implications for individuals' human capital and wages, but without considering the link with the aggregate changes in employment shares for different occupations. Some examples from this literature include MoscarinI, THOMsson (2007); Kambourov, ManovskiI (2008); Poletaev, Robinson (2008); Kambourov, Manovskit (2009); Gathmann, Schönberg (2010); Sullivan (2010); Groes et al. (2015); CoRTes, GALlipoli (2018).
} 
propensity to be out of employment (either unemployed or out of the labor force), and in the propensity to work in non-routine manual occupations. Interestingly, the changes experienced by this relatively small subset of demographic groups account not only for much of the decline in routine employment, but also for a substantial fraction of the increase in non-employment and in non-routine manual employment observed in the U.S. over recent decades.

\section{Grouping Occupations: Task-Based Approach}

I begin by providing a brief overview of the way in which occupations can be grouped following the task-based approach. The literature, starting with AUTOR et al. (2003), has highlighted the usefulness of classifying occupations according to their task content. Researchers have generally focused on two dimensions of tasks: "cognitive" versus "manual," and "routine" versus "non-routine." The distinction between cognitive and manual occupations is based on the extent of mental versus physical activity. The distinction between routine and non-routine is based on whether the tasks involved can be summarized as a set of specific activities accomplished by following well-defined instructions. If this is the case, the occupation is considered routine. If instead the job requires flexibility, creativity, problem-solving, or human interaction, the occupation is non-routine.

ACEMOGLu and Autor (2011) discuss how occupations can be readily grouped into task categories based on their broad occupational classification. Specifically, the four major task groups can be delineated as follows:

- Non-Routine Cognitive (NRC): professional, technical, management, business and financial occupations.

- Routine Cognitive (RC): clerical, administrative support, sales workers.

- Routine Manual (RM): craftsmen, foremen, operatives, installation, maintenance and repair occupations, production and transportation occupations, laborers.

- Non-Routine Manual (NRM): service workers.

Table 1 provides examples of specific occupations included in each category, based on the mapping used in Section 3 of this paper, which combines routine cognitive and routine manual occupations into a single routine category. ${ }^{3}$ Table 2 illustrates the differences across the three occupation groups using data for male household heads from the Panel Study of Income Dynamics (PSID). The first clear pattern that emerges is that routine jobs are middle-wage jobs: in all three sub-periods, mean real wages are highest in non-routine cognitive occupations and lowest in non-routine manual ones. It is also clear that non-routine cognitive jobs are the most skill-intensive: in all three sub-periods, they have a substantially higher share of college educated workers as compared to the other two occupational groups.

3. See CORTES et al. (2014) for details on the exact mapping. 
TABLE 1 - Occupation Code Groupings

\begin{tabular}{|c|c|c|c|}
\hline \multirow{2}{*}{ Task Label } & \multirow{2}{*}{ Occcupations Included } & \multicolumn{2}{|c|}{ 3-digit Census Codes } \\
\hline & & 1970-COC & 2000-COC \\
\hline \multirow[t]{5}{*}{ Non-Routine Cognitive } & Professional, technical and kindred workers & $001-195$ & \\
\hline & Professional and related occupations & & $100-354$ \\
\hline & Managers, officials and proprietors, except farm & $201-245$ & \\
\hline & Management, business and financial occupations & & 001-095 \\
\hline & Managers of retail and non-retail sales workers & & $470-471$ \\
\hline \multirow[t]{11}{*}{ Routine } & Sales workers, except managers & $260-285$ & $472-496$ \\
\hline & Clerical and kindred workers & $301-395$ & \\
\hline & Office and administrative support occupations & & $500-593$ \\
\hline & Craftsmen, foremen and kindred workers & $401-575$ & \\
\hline & Operatives, except transport & $601-695$ & \\
\hline & Laborers, except farm & $740-785$ & \\
\hline & Construction and extraction occupations & & $620-694$ \\
\hline & Installation, maintenance and repair occupations & & $700-762$ \\
\hline & Production occupations & & $770-896$ \\
\hline & Transport equipment operatives & $701-715$ & \\
\hline & Transportation and material moving occupations & & $900-975$ \\
\hline Non-Routine Manual & Service workers & $901-984$ & $360-465$ \\
\hline \multirow[t]{3}{*}{ Not classified } & Members of armed forces & 600 & 984 \\
\hline & Farmers, farm managers, farm laborers, farm foremen & $801-824$ & \\
\hline & Farming, fishing and forestry occupations & & $600-613$ \\
\hline
\end{tabular}

Note: $\mathrm{COC}=$ Census Occupation Codes. Details on the 3-digit codes are available from IPUMS (KING et al., 2010): https://usa.ipums. org/usa/volii/97occup.shtml for the 1970 codes and https://usa.ipums.org/usa/volii/occ2000.shtml for the 2000 codes (accessed 21 May 2019).

Source: CORTES (2016) Online Appendix.

TABLE 2 - Descriptive Statistics

\begin{tabular}{|c|c|c|c|c|c|c|c|c|c|}
\hline & \multicolumn{3}{|c|}{ Non-Routine Cognitive } & \multicolumn{3}{|c|}{ Routine } & \multicolumn{3}{|c|}{ Non-Routine Manual } \\
\hline & $\begin{array}{c}1976- \\
1986\end{array}$ & $\begin{array}{c}1987- \\
1996\end{array}$ & $\begin{array}{l}1997- \\
2007\end{array}$ & $\begin{array}{c}1976- \\
1986\end{array}$ & $\begin{array}{c}1987- \\
1996\end{array}$ & $\begin{array}{c}1997- \\
2007\end{array}$ & $\begin{array}{c}1976- \\
1986\end{array}$ & $\begin{array}{c}1987- \\
1996\end{array}$ & $\begin{array}{c}1997- \\
2007\end{array}$ \\
\hline Employment Share & 0.40 & 0.44 & 0.42 & 0.54 & 0.50 & 0.49 & 0.06 & 0.06 & 0.09 \\
\hline Average Wages & 10.47 & 11.82 & 13.78 & 7.07 & 6.78 & 7.30 & 5.65 & 5.82 & 6.27 \\
\hline \multicolumn{10}{|c|}{ Fractions within the occupation group: } \\
\hline High School Dropout & 0.03 & 0.01 & 0.01 & 0.22 & 0.14 & 0.10 & 0.13 & 0.10 & 0.08 \\
\hline High School Graduate & 0.15 & 0.15 & 0.16 & 0.49 & 0.54 & 0.52 & 0.42 & 0.44 & 0.42 \\
\hline Some College & 0.19 & 0.22 & 0.24 & 0.22 & 0.23 & 0.26 & 0.33 & 0.33 & 0.34 \\
\hline College & 0.63 & 0.62 & 0.59 & 0.08 & 0.09 & 0.12 & 0.12 & 0.13 & 0.16 \\
\hline \multicolumn{10}{|l|}{ Task measures: } \\
\hline Non-Routine Cognitive & 6.08 & 6.01 & 5.95 & 1.81 & 1.82 & 1.88 & 1.31 & 1.32 & 1.21 \\
\hline Routine & 3.17 & 2.99 & 2.95 & 4.81 & 4.70 & 4.46 & 2.35 & 2.30 & 2.31 \\
\hline Non-Routine Manual & 0.72 & 0.76 & 0.78 & 1.89 & 1.86 & 1.82 & 2.47 & 2.32 & 2.31 \\
\hline
\end{tabular}

Note: Sample includes male household heads aged 16 to 64 employed in non-agricultural, non-military jobs, who are part of the $P S I D$ 's core sample and have non-missing wage data. Average wages are in constant 1979 dollars. The task measures are from the Dictionary of Occupational Titles (DOT) 4th Edition, published in 1977 (NATIONAL ACADEMY OF SCIENCE, COMMITTEE ON OCCUPATIONAL ClassifiCATION AND ANALYSIS, 1977, 1981). DOT task measures are aggregated to 1970 Census Occupation Codes (COC), rescaled to have a (potential) range from zero to 10 , and attached to the occupation codes observed in the data at the individual level. The average task measures for the post-1997 period are for 1997-2001, as task measures at the 1970-COC level cannot be attached to PSID data from 2003 onwards (when occupations are coded in 2000 Census codes).

Source: CORTES (2016). 
The bottom three lines of Table 2 illustrate the task content measures that justify the name that has been given to each category. These task measures are obtained from the Dictionary of Occupational Titles (National Academy of Science, CommitTeE on OcCuPATIONAL Classification and ANALYsis, 1977, 1981), which records a large amount of information about the tasks that are important for successful job performance in different occupations. Following Autor, LEVY, and Murnane (2003), non-routine cognitive tasks are measured as the mean score for the importance of "mathematics" and "direction, control and planning". Routine tasks are captured by the mean importance of "dealing with set limits, tolerances and standards" and "finger dexterity", while non-routine manual tasks are measured based on the importance of "eye-hand-foot coordination". The table clearly shows that the occupations that we have categorized as non-routine cognitive are most intensive in these tasks; middle-wage routine occupations are most intensive in routine tasks; and non-routine manual occupations are most intensive in non-routine manual tasks. Similar task content patterns can be obtained from the $\mathrm{O}^{*}$ Net dataset, which is the successor to the Dictionary of Occupational Titles (ACEMOGLu, Autor, 2011).

\section{Tracking Individuals over Time: Where Do Male Routine Workers Go?}

This section presents results based on data from the Panel Study of Income Dynamics (PSID). The PSID is a longitudinal dataset which has tracked a sample of individuals and their offspring since 1977. This dataset makes it possible to analyze individual workers' occupational mobility patterns and wage trajectories over different time horizons. ${ }^{4}$ The analysis in CORTES (2016), which is discussed in this section, focuses on male household heads in the PSID, aged between 16 and 64, employed in non-agricultural, non-military jobs, and observed between 1977 and 2005. Before discussing the empirical results, the next sub-section outlines a theoretical framework that helps organize our thoughts about the predicted effects of routine-biased technical change (RBTC) on wage changes and occupational switches at the individual level.

\section{Theoretical Framework: Impacts of Technological Change on Employed Workers}

Consider an economy with a continuum of workers who differ in terms of their skill levels. Workers may sort into one of three occupations: non-routine manual, routine and non-routine cognitive. Each individual worker's wage will depend both

\footnotetext{
4. The PSID is primarily sponsored by the National Science Foundation, the National Institute of Aging, and the National Institute of Child Health and Human Development and is conducted by the University of Michigan. PSID data is publicly available at http://PSIDonline.isr.umich.edu/ (accessed 21 May 2019). More details on the data are provided in CORTES (2016).
} 
on their skill level, and on the task that they perform. Workers of higher skill levels are assumed to be particularly productive at more complex non-routine cognitive tasks.

In such a model, workers will sort into occupations as illustrated in Panel A of Figure $1 .^{5}$ The lines in the Figure represent potential wages in each occupation. The assumption that workers of higher skill levels are particularly productive at non-routine cognitive tasks is reflected in the fact that the potential wage curve is steepest in that occupation, and flattest for the non-routine manual occupation. The equilibrium of the model features two endogenously determined skill thresholds, such that the least skilled workers find it optimal to select into the non-routine manual occupation; the middle-skilled workers into the routine occupation; and the most skilled workers into the non-routine cognitive occupation. In equilibrium, average real wages are lowest among non-routine manual workers, and highest among non-routine cognitive workers, which is consistent with the data.

RBTC is modeled as an exogenous shock which decreases the relative demand for labor performing routine tasks and increases the relative demand for labor performing non-routine cognitive tasks. The predicted effects of RBTC are illustrated in Panel B of Figure 1. The shock shifts down the potential wage curve for the routine occupation and shifts up the potential wage curve for the non-routine cognitive occupation. In the new equilibrium, the ability thresholds shift, such that employment in both types of non-routine occupations expands, while employment in the routine occupation contracts. As the skill cutoff between routine and non-routine cognitive tasks falls, the highest ability routine workers will be the ones who find it optimal to switch to non-routine cognitive jobs (due to comparative advantage). Meanwhile, the increase in the skill cutoff between non-routine manual and routine tasks implies that it is the lowest ability routine workers who find it optimal to switch to non-routine manual tasks. Workers switching out of routine jobs must do at least as well in terms of wage growth as those who stay, as they could have chosen to stay in the routine occupation but find it optimal not to do so.

To summarize, the model provides the following predictions for the impact of RBTC: (i) workers at the bottom of the ability distribution within routine occupations switch to non-routine manual jobs, workers at the top of the ability distribution within routine occupations switch to non-routine cognitive jobs, (ii) workers staying in routine jobs experience a fall in real wages relative to those staying in other jobs, and workers staying in non-routine cognitive jobs experience an increase in real wages relative to those staying in other jobs, and (iii) workers who switch from routine to non-routine jobs (either cognitive or manual) experience an increase in real wages relative to those who stay in the routine occupation.

5. See also GiBbons et al. (2005) for a framework with the same type of sorting mechanism. 
FIGURE 1 - Equilibrium Relationship between Skills, Occupational Choices and Wages, and Effects of Routine-Biased Technical Change

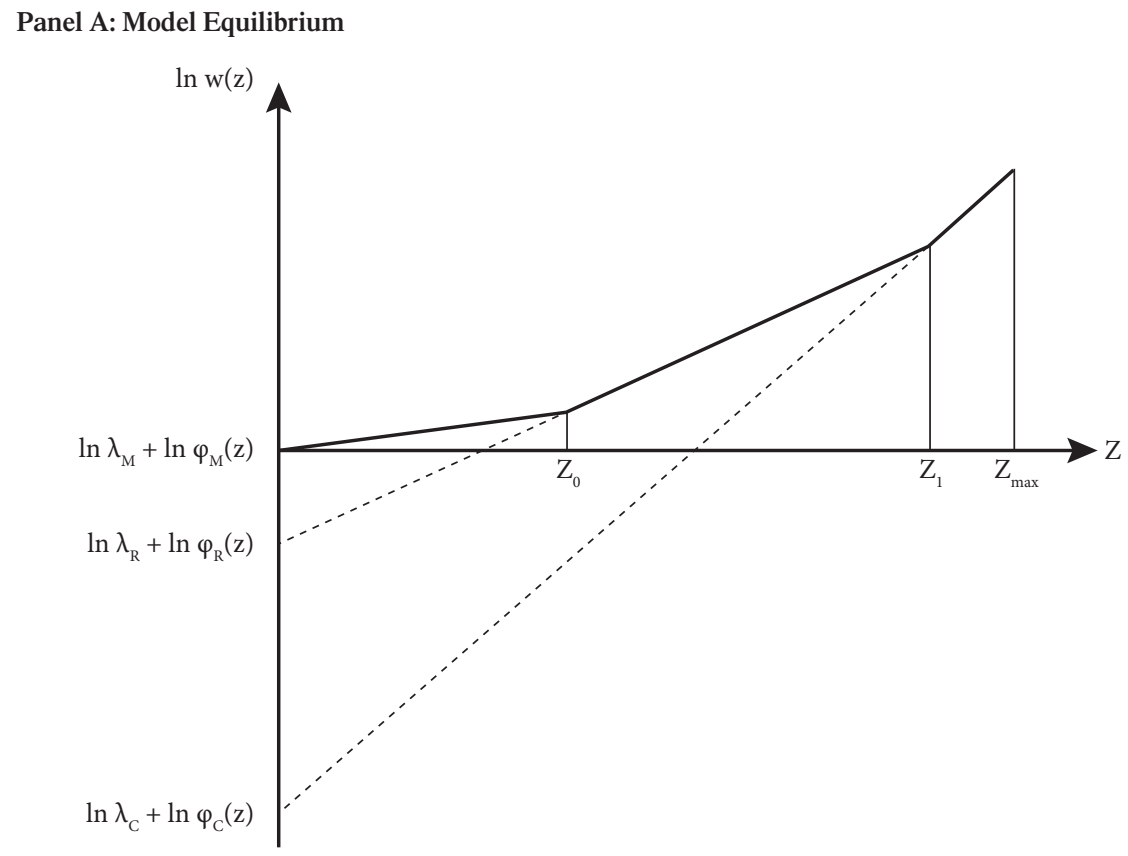

Panel B: Effects of Routine-Biased Technical Change

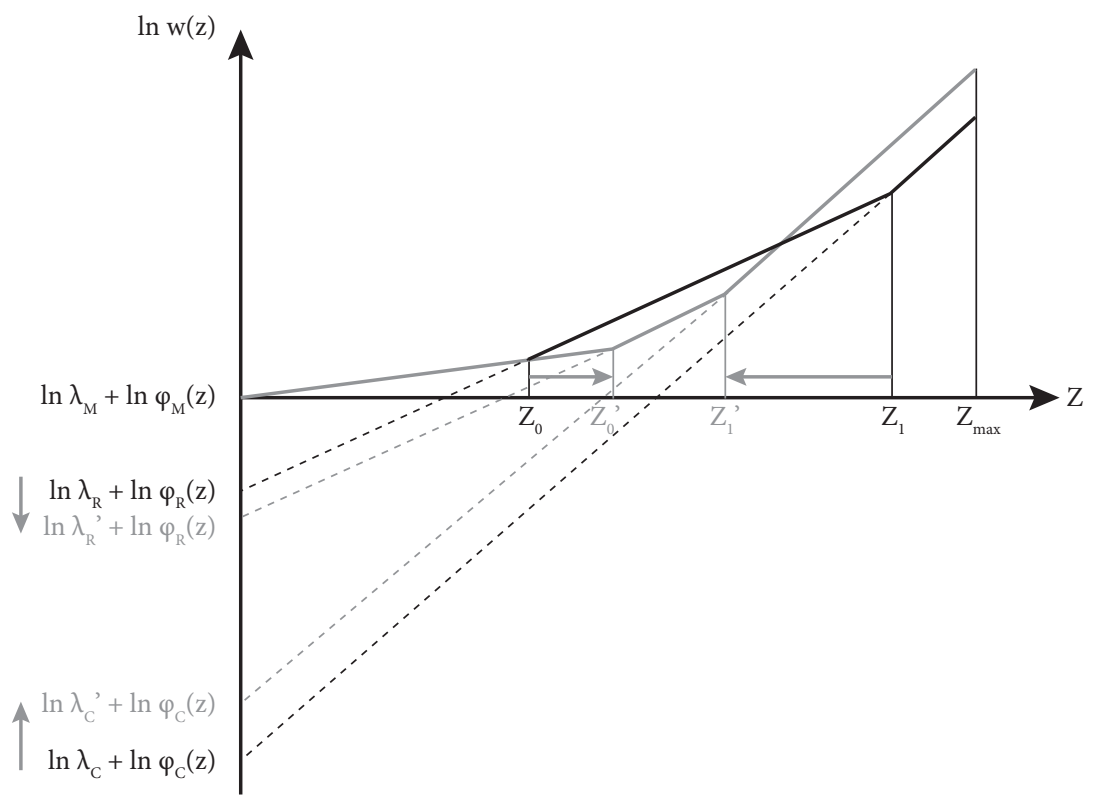

Source: CORTES (2016). 


\section{Empirical Evidence: Occupational Mobility Patterns}

In CORTES (2016), I estimate a series of wage regressions in order to obtain individual-specific occupation spell fixed effects which allow me to rank workers according to their position within the wage distribution in their occupation, after controlling for a number of observable characteristics. I interpret their relative position in the estimated occupation spell distribution as a proxy for their relative ability, and use these estimates to rank workers into ability quintiles within their occupation. I then determine the probability that an individual will switch out of a routine job, according to their position in this distribution.

Figure 2 plots the probability of switching occupations by ability quintile for two different periods: 1977-1989 and 1991-2005. The fraction of switchers is calculated over two year windows; that is, each bar indicates the fraction of workers from ability quintile $q$ who switch out of routine occupations between period $t$ and period $t+2$. Only odd years are used to generate the graph. These restrictions are imposed in order to ensure comparability with the period from 1997 onwards, when the PSID became bi-annual. The fraction of switchers is calculated over the total number of workers from each quintile who have valid occupation reports in years $t$ and $t+2$.

\section{FIGURE 2 - Exit Probabilities by Ability Quintile, Routine Workers}

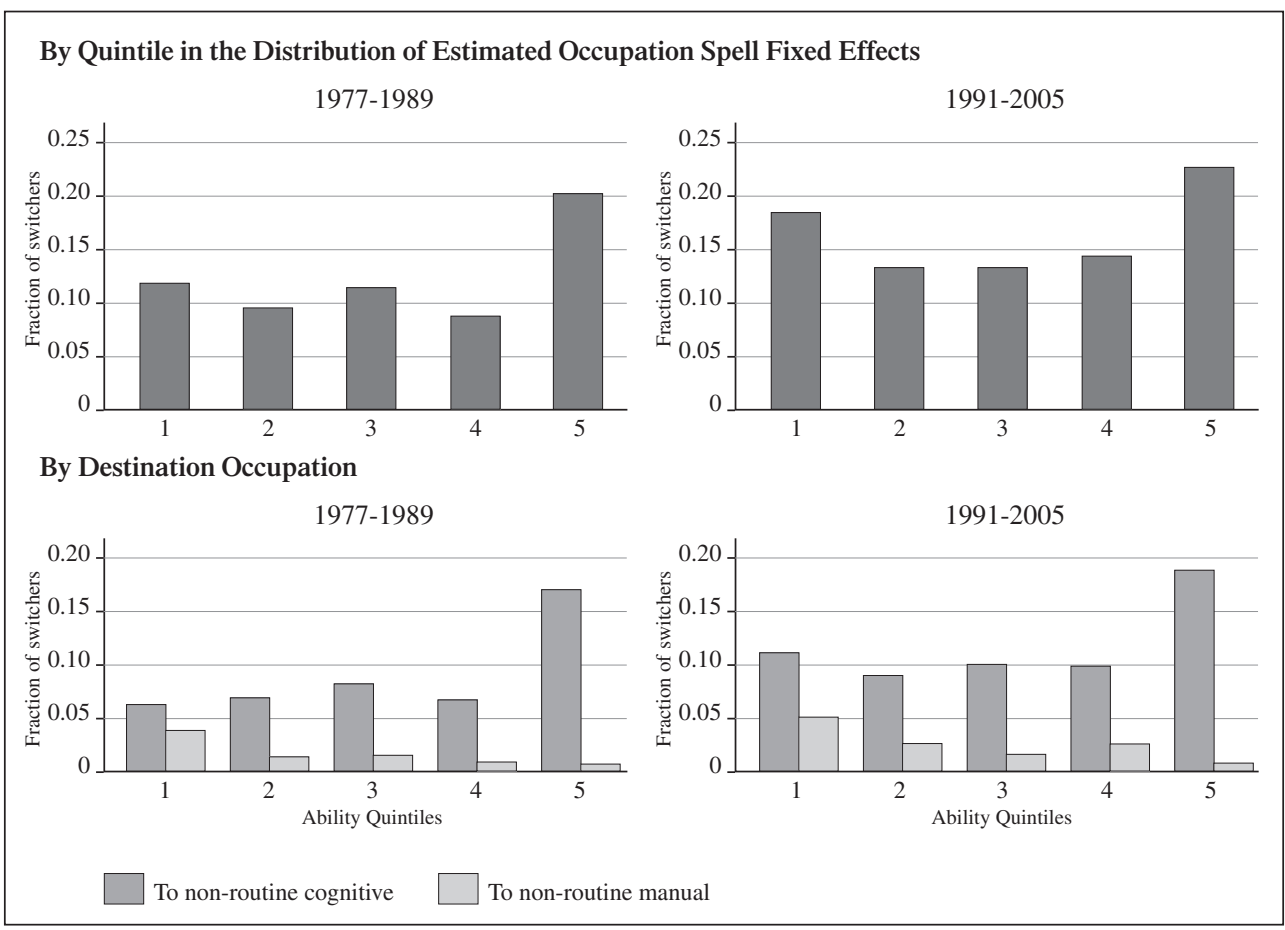

Note: Sample includes male workers in routine occupations, and plots their probability of switching out of this type of occupation between years $t$ and $t+2$, according to their ability quintile.

Source: Data from PSID, see CORTES (2016). 
The figure shows that the highest ability workers are more likely to switch out of routine jobs compared to lower ability workers in both sub-periods. This difference is statistically significant. After 1991, the probability of switching increases for workers of all ability levels, but the increase is particularly strong for lower ability workers. This leads to a U-shaped pattern in the probability of switching after 1991.

In the bottom panels of Figure 2, I analyze the direction of the switches occurring at each quintile of the ability distribution. Switchers from all quintiles are more likely to go to non-routine cognitive jobs than to non-routine manual ones. This would be expected even if the direction of switch were random, as the non-routine cognitive occupation is much larger in terms of employment than the non-routine manual one. However, there is a clear pattern of selection according to ability quintiles. Consistent with the prediction of the model, the probability of switching to non-routine manual jobs is decreasing in ability, while the probability of switching to non-routine cognitive

FIGURE 3 - Direction of Switch by Ability Quintile, Non-Routine Workers

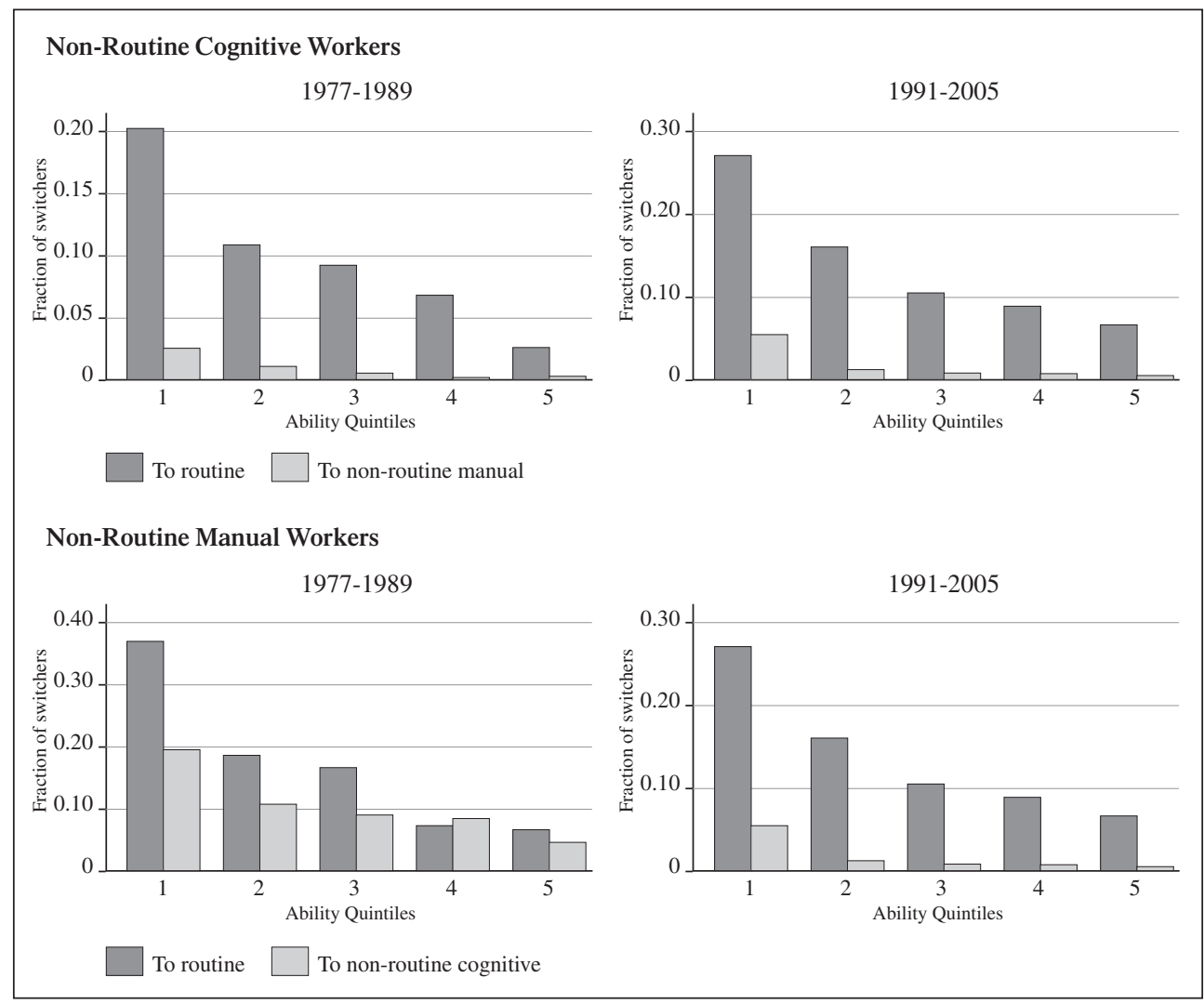

Note: Sample includes male workers in non-routine occupations, and plots their probability of switching out of this type of occupation between years $t$ and $t+2$, according to their ability quintile.

Source: Data from PSID, see CORTES (2016). 
jobs is increasing in ability. ${ }^{6}$ The differences in switching probabilities across quintiles are statistically significant during both sub-periods.

These results for routine workers can be contrasted with the switching patterns for workers in non-routine occupations. These are presented in Figure 3. Among nonroutine workers we do not observe the U-shaped mobility pattern that is observed for routine workers; instead it is only the low ability workers who are disproportionately likely to switch occupations.

\section{Empirical Evidence: Wage Changes}

Next, I analyze the wage outcomes for different workers. I consider first the wage changes for workers who do not switch occupations. These are particularly relevant, as they capture changes in the return to an occupation (i.e. the occupation wage premium) that are purged of compositional changes occurring within the occupation. In general, average wages within an occupation may change due to the fact that workers with certain characteristics leave an occupation while other workers enter the occupation. By focusing only on continuing workers, one can obtain a composition-adjusted estimate of the change in the return to a particular occupation. ${ }^{7}$

FIGURE 4 - Estimated Changes in Occupational Returns

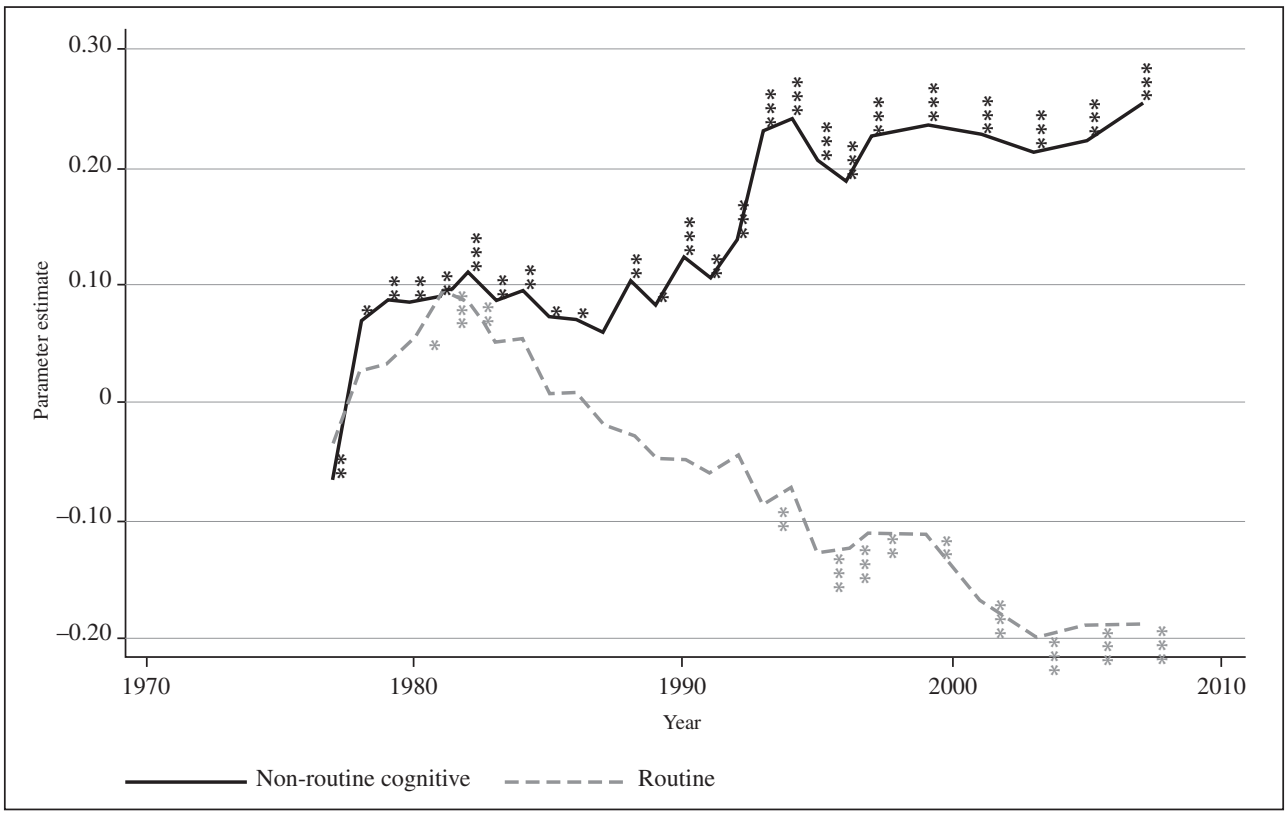

Note: Estimated coefficients on composition-adjusted occupation-year fixed effects. Stars denote the level at which the estimated coefficients are significantly different from zero $(*=10 \%, * *=5 \%$, *** $=1 \%)$.

Source: Data from PSID, see CORTES (2016).

6. See GroEs et al. (2015) for evidence of related patterns using administrative data from Denmark.

7. For related exercises, see Böнм (2017) and GotTschaLK et al. (2015). 
Figure 4 plots the estimates of the composition-adjusted changes in occupational returns, relative to the non-routine manual occupation. From the early 1980s onwards, the estimated return to routine occupations has a clear downward trend. Meanwhile, the corresponding return for non-routine cognitive occupations shows an upward trend, particularly from the 1990s onwards. This is consistent with the predictions of the model. Note that all of the coefficients for the later periods are significantly different from zero. The magnitude of the fall in the occupation wage premium for routine jobs is substantial. The fall from its peak in the early 1980s until the mid-2000s is similar in magnitude to the estimated rise in the college wage premium over that period.

Next, I study the wage changes for routine workers who follow different switching patterns. Table 3 presents the results of a number of wage regressions where the sample is restricted to routine workers only (both stayers and switchers). The dependent variable is the wage change, and the regressors are dummies for the direction of occupational switching (either to non-routine cognitive or to non-routine manual). Staying in routine jobs is the omitted category. The estimated coefficients reflect the differential wage growth for each type of switcher, relative to the stayers. Column (1) defines switchers and stayers based on individuals' occupational codes in years $t$ and $t+1$, while the remaining columns are based on the codes in years $t$ and $t+2$.

The results show that wage growth is significantly lower over horizons up to two years for workers who switch to non-routine manual jobs. When considering longer horizons (10 years), however, the differential becomes positive and significant. For example, when using fitted model wages, workers switching from a routine job in year $t$ to a non-routine manual job in year $t+2$ experience a wage change that is $14 \%$ lower than that experienced by stayers in routine jobs. By year $t+10$ however, the wage change for these workers is $5 \%$ above that of stayers. This result is not driven by changes in the composition of the workers included in the different regressions, as discussed in detail in CORTES (2016).

Over all time horizons, those who switch to non-routine cognitive jobs experience significantly faster wage growth than stayers. Fitted model wages grow $12 \%$ faster over a two-year period for switchers to non-routine cognitive occupations, relative to those who stay in routine jobs. The figure is similar (14\%) over a 10 year horizon.

The findings presented so far on the wage growth of workers switching out of routine jobs are consistent with the predictions of the model. However, one potential concern is the possibility that occupational switching may simply reflect career progression. It might be the case that, regardless of the type of transition made, workers who switch occupations experience faster wage growth than stayers in the long run. To rule out this concern, in CORTES (2016) I replicate the analysis from Table 3 for the sample of non-routine workers and show that there is no evidence that switching occupations is generally beneficial. In fact, switchers out of non-routine cognitive occupations suffer wage losses over all time horizons considered, regardless of the direction of switch. 
TABle 3 - Wage Changes for Routine Workers, According to Direction of Switch

\section{Panel A: Dependent Variable is Change in Log Real Wages}

Change in Log Real Wages between Year $t$ and Year:

\begin{tabular}{lcccc|cc} 
& $t+1$ & $t+2$ & $t+4$ & $t+10$ & $t+2$ & $t+2$ \\
\cline { 2 - 7 } Period & $1976-1997$ & $1976-2007$ & $1976-2007$ & $1976-2007$ & $1977-1991$ & $1991-2007$ \\
\hline & $(1)$ & $(2)$ & $(3)$ & $(4)$ & $(5)$ & $(6)$ \\
\hline To non-routine cognitive & 0.034 & 0.059 & 0.085 & 0.163 & 0.022 & 0.088 \\
& $(0.008)^{* * * *}$ & $(0.008)^{* * *}$ & $(0.010)^{* * * *}$ & $(0.019)^{* * *}$ & $(0.016)$ & $(0.012)^{* * *}$ \\
To non-routine manual & -0.112 & -0.143 & -0.035 & 0.115 & -0.134 & -0.123 \\
& $(0.023)^{* * * *}$ & $(0.023)^{* * *}$ & $(0.026)$ & $(0.046)^{* * *}$ & $(0.039)^{* * *}$ & $(0.033)^{* * * *}$ \\
Constant & 0.037 & 0.066 & 0.016 & -0.002 & 0.026 & 0.041 \\
Observations & $(0.007)^{* * * *}$ & $(0.009)^{* * *}$ & $(0.011)$ & $(0.018)$ & $(0.009)^{* * *}$ & $(0.010)^{* * *}$ \\
Number of Individuals & 15800 & 18341 & 14278 & 7568 & 4754 & 6701 \\
$R^{2}$ & 2655 & 3253 & 2701 & 1735 & 1609 & 2234 \\
\hline
\end{tabular}

Panel B: Dependent Variable is Change in Fitted Model Wages (in Logs)

Change in Fitted Model Wages between Year $t$ and Year:

\begin{tabular}{lcccc|cc} 
& $t+1$ & $t+2$ & $t+4$ & $t+10$ & $t+2$ & $t+2$ \\
\cline { 2 - 7 } Period & $1976-1997$ & $1976-2007$ & $1976-2007$ & $1976-2007$ & $1976-1991$ & $1991-2007$ \\
\hline & $(1)$ & $(2)$ & $(3)$ & $(4)$ & $(5)$ & $(6)$ \\
\hline To non-routine cognitive & $0.086 * *$ & 0.122 & 0.098 & 0.139 & 0.051 & 0.184 \\
& $(0.010)^{* * * *}$ & $(0.009)^{* * *}$ & $(0.008)^{* * *}$ & $(0.011)^{* * *}$ & $(0.014)^{* * * *}$ & $(0.012)^{* * *}$ \\
To non-routine manual & -0.152 & -0.139 & -0.030 & 0.054 & -0.151 & -0.115 \\
& $(0.023)^{* * * *}$ & $(0.021)^{* * *}$ & $(0.019)$ & $(0.027)^{* * *}$ & $(0.037)^{* * * *}$ & $(0.028)^{* * * *}$ \\
Constant & -0.038 & 0.026 & 0.049 & -0.014 & 0.067 & -0.034 \\
Observations & $(0.002)^{* * * *}$ & $(0.003)^{* * *}$ & $(0.004)^{* * *}$ & $(0.008)^{*}$ & $(0.003)^{* * *}$ & $(0.004)^{* * *}$ \\
Number of Individuals & 15800 & 18341 & 14278 & 7568 & 4754 & 6701 \\
$R^{2}$ & 2655 & 3253 & 2701 & 1735 & 1609 & 2234 \\
\hline
\end{tabular}

Panel C: Fraction of Routine Workers in Each of the Switching Categories (\%)

Fraction of Routine Workers in Year $t$ Switching to Non-Routine Jobs in Year:

\begin{tabular}{lcccc|cc} 
& $t+1$ & $t+2$ & $t+2$ & $t+2$ & $t+2$ & $t+2$ \\
\cline { 2 - 7 } Period & $1976-1997$ & $1976-2007$ & $1976-2007$ & $1976-2007$ & $1977-1991$ & $1991-2007$ \\
\hline & $(1)$ & $(2)$ & $(3)$ & $(4)$ & $(5)$ & $(6)$ \\
\hline To non-routine cognitive & 8.07 & 10.95 & 11.26 & 11.47 & 9.82 & 13.10 \\
To non-routine manual & 1.51 & 2.18 & 1.92 & 1.88 & 1.83 & 2.75 \\
\hline
\end{tabular}

Note: Workers who stay in routine occupations are the omitted category. All regressions include year dummies. The wage changes are taken over the time horizons indicated above each column (in years). For column (1), occupation transitions between years $t$ and $t+1$ are considered. For column (2) onwards, occupation transitions between years $t$ and $t+2$ are considered (even though the wage change may be taken over a longer horizon). Columns (5) and (6) use odd years only. Observations with log real hourly wages below 0.1 (\$1.1 1979 dollars) or above 4 (\$54.6 1979 dollars) are excluded. Standard errors are clustered at the individual level.

* Statistically different from zero at the $10 \%$ level.

** Statistically different from zero at the $5 \%$ level.

*** Statistically different from zero at the $1 \%$ level.

Source: CORTES (2016). Panel A uses changes in real wages, while Panel B uses changes in fitted model wages (changes over time in the estimated occupation spell fixed effects for each individual). For reference purposes, Panel C reports the percentage of routine workers classified into each of the switching categories. 
To summarize, the results show that (conditional on remaining employed), it is workers who remain in routine jobs who are most hardly hit in terms of their long-run wage growth. Workers who transition out of routine occupations, regardless of the direction of switch, experience faster long-run wage growth than those who stay.

\section{Tracking Demographic Groups: Which Groups Drive the Decline in Routine Employment?}

The analysis in the previous section focuses only on employed workers. However, it is clear that many workers who might have been able to find employment in routine jobs in the past are no longer able to do so. In this section, I discuss the findings from CORTES, JAIMOVICH, and SIU (2017), where we use nationally representative data from the Monthly Current Population Survey (CPS) -the main source of U.S. labor market statistics- in order to determine which demographic groups are most impacted by the decline of routine employment. ${ }^{8}$

\section{Changes in Routine Employment: Demographic Composition vs Propensities}

We begin our analysis by determining the importance of aggregate changes in the demographic composition of the population in accounting for the decline in per capita routine employment. We classify individuals into 24 groups based on their age (three groups: 20-29, 30-49, 50-64, which we refer to as the young, prime-aged, and old respectively), education (four groups: less than high school, high school graduates, some college, and college graduates), and gender. The change in the fraction of the population in state $j$ between period 0 and period 1 can be decomposed as follows:

$$
\bar{\pi}_{t}^{j}=\sum_{g} w_{g t} \pi_{g t}^{j},
$$

where $w_{g t}$ is the fraction of individuals of demographic group $g$ at time $t$, and $\pi_{g t}^{j}$ is the fraction of individuals of demographic group $g$ in state $j$ at time $t$. We consider five labor market states: employment in one of the four occupation groups (non-routine cognitive, routine cognitive, routine manual, or non-routine manual), and non-employment (which includes unemployment and labor force non-participation).

The change in the fraction of the population in state $j$ can be decomposed as follows:

$$
\bar{\pi}_{1}^{j}-\bar{\pi}_{0}^{j}=\sum_{g} w_{g 1} \pi_{g 1}^{j}-\sum_{g} w_{g 0} \pi_{g 0}^{j}=\sum_{g} \Delta w_{g 1} \pi_{g 0}^{j}+\sum_{g} w_{g 0} \Delta \pi_{g 1}^{j}+\sum_{g} \Delta w_{g 1} \Delta \pi_{g 1}^{j} \text {. }
$$

8. The CPS data is made available through IPUMS (FLOOD et al., 2015). As above, we focus on the civilian, noninstitutionalized population aged 20 to 64 years old, excluding those employed in agriculture and resource occupations. In CORTES et al. (2014), we exploit the limited longitudinal dimension of the CPS in order to construct worker flows into and out of routine employment, and we analyze the relative importance of changes in the different flows in accounting for the decline in routine employment. 
The first term is the composition effect, which captures the portion that is driven by changes in the population shares of different demographic groups. The second component is the propensity effect, which captures the portion that is driven by changes in the fraction of individuals from group $g$ that are in state $j$. The third term is an interaction effect.

The results of this decomposition are presented in Table 4. In Panel A we focus on the period that features a strong decline in per capita employment in Routine Manual (RM) occupations: 1979-2014. In Panel B we focus on the period that features a strong decline in per capita employment in Routine Cognitive (RC) occupations: 1989-2014. The observed fraction of the population in each of the five labor market states is displayed in Columns (1) and (2), with the total change displayed in Column (3).

TABLE 4 - Decompositions Based on Age-Education-Gender Groups

\begin{tabular}{|c|c|c|c|c|c|c|}
\hline & \multirow[b]{2}{*}{ Pre } & \multirow[b]{2}{*}{ Post } & \multicolumn{4}{|c|}{ Difference } \\
\hline & & & Total & Composition & Propensity & Interaction \\
\hline & (1) & (2) & (3) & (4) & (5) & (6) \\
\hline \multicolumn{7}{|l|}{ Panel A: 1979-2014 } \\
\hline Number of Observations & 976,672 & 922,931 & & & & \\
\hline $\operatorname{NRC}(\%)$ & 21.5 & 28.2 & +6.7 & +9.7 & -2.9 & -0.0 \\
\hline $\mathrm{RC}(\%)$ & 17.3 & 16.1 & -1.2 & +0.6 & -2.0 & +0.3 \\
\hline $\mathrm{RM}(\%)$ & 23.2 & 15.1 & -8.1 & -5.2 & -5.7 & +2.7 \\
\hline $\operatorname{NRM}(\%)$ & 8.4 & 12.3 & +3.9 & -1.9 & +6.6 & -0.8 \\
\hline Not Working (\%) & 29.6 & 28.3 & -1.3 & -3.1 & +4.0 & -2.2 \\
\hline \multicolumn{7}{|l|}{ Panel B: 1989-2014 } \\
\hline Number of Observations & 977,282 & 922,931 & & & & \\
\hline $\operatorname{NRC}(\%)$ & 24.7 & 28.2 & +3.5 & +6.3 & -2.7 & -0.1 \\
\hline $\mathrm{RC}(\%)$ & 19.6 & 16.1 & -3.5 & +0.3 & -3.9 & +0.2 \\
\hline $\mathrm{RM}(\%)$ & 21.0 & 15.1 & -5.9 & -3.5 & -4.0 & +1.6 \\
\hline $\operatorname{NRM}(\%)$ & 9.6 & 12.3 & +2.7 & -1.7 & +4.7 & -0.3 \\
\hline Not Working $(\%)$ & 25.2 & 28.3 & +3.1 & -1.4 & +5.9 & -1.3 \\
\hline
\end{tabular}

Note: NRC stands for Non-Routine Cognitive, RC for Routine Cognitive, RM for Routine Manual, and NRM for Non-Routine Manual. Column (1) shows the composition for the initial period (1979 in Panel A; 1989 in Panel B); Column (2) shows the composition for the final period (2014 in both Panels). Column (3) shows the total change for the entire period, which is decomposed into the fraction attributable to changes in the composition of demographic groups in the population (Column (4)), changes in the propensity to enter the different categories conditional on demographic characteristics (Column (5)), and the interaction of the two (Column (6)).

Source: CoRTES, JAIMOVICH, and SiU (2017). Composition of the population across different occupational groups and not working, based on individuals aged 20-64 from the monthly Current Population Survey, excluding those employed in agriculture and resource occupations.

Panel A shows a decline in per capita Routine Manual (RM) employment of 8.1 percentage points between 1979 and 2014. Although part of it is due to composition change (mainly related to the reduction in the share of the population with at most high school education), a greater proportion is driven by changes in propensities. Meanwhile, the decline in per capita Routine Cognitive (RC) employment in Panel B is entirely driven by the propensity effect. In fact, demographic change would have predicted an increase in the fraction of the population employed in routine cognitive occupations. 


\section{Which Demographic Groups Account for the Decline in Routine Employment?}

In order to determine which demographic groups account for the decline in per capita routine employment, we compute the change induced by each group $g$, $w_{g 1} \pi_{g 1}^{j}-w_{g 0} \pi_{g 0}^{j}$ from Equation (2), as a fraction of the total change.

The results for routine manual employment are presented in Panel A of Table 5. Five groups account for $94 \%$ of the fall in routine manual employment: male high school dropouts of all ages and male high school graduates under the age of 50.

TABLE 5 - Fraction of change accounted for by each demographic group

Panel A: Routine Manual Employment, 1979-2014

\begin{tabular}{lccc|ccc} 
& \multicolumn{3}{c}{ Males } & \multicolumn{3}{c}{ Females } \\
\hline Less Than High School & $20-29$ & $30-49$ & $50-64$ & $20-29$ & $30-49$ & $50-64$ \\
High School Diploma & $\mathbf{1 0 . 2 6}$ & $\mathbf{1 9 . 6 0}$ & $\mathbf{1 8 . 6 6}$ & 3.60 & 8.41 & 5.60 \\
& $\mathbf{3 0 . 8 6}$ & $\mathbf{1 4 . 8 8}$ & -4.03 & 7.39 & 6.62 & 0.30 \\
Some College & & All Ages & & \multicolumn{3}{c}{ All Ages } \\
At Least College & -13.55 & & \multicolumn{3}{c}{-2.88} \\
\hline
\end{tabular}

Panel B: Routine Cognitive Employment Propensity, 1989-2014

\begin{tabular}{lccc|ccc} 
& \multicolumn{3}{c}{ Males } & \multicolumn{3}{c}{ Females } \\
\hline High School Diploma & $20-29$ & $30-49$ & $50-64$ & $20-29$ & $30-49$ & $50-64$ \\
Some College & -2.35 & 3.16 & 3.13 & $\mathbf{1 4 . 8 0}$ & $\mathbf{2 4 . 1 3}$ & 3.54 \\
& 2.15 & 5.43 & 2.38 & $\mathbf{1 2 . 2 7}$ & $\mathbf{1 0 . 6 2}$ & 1.50 \\
Less Than High School & & All Ages & & \multicolumn{3}{c}{3.37} \\
At Least College & \multicolumn{3}{c}{0.65} & & \multicolumn{3}{c}{6.46} \\
\hline
\end{tabular}

Note: Panel A presents the fraction of the total change in the population share of Routine Manual (RM) employment that can be attributed to the changes experienced by each demographic group (by age, education and gender). Panel B presents the fraction of the total change in the propensity to work in a Routine Cognitive (RC) occupation that can be attributed to each demographic group. The analysis is based on individuals aged 20-64 from the monthly Current Population Survey, excluding those employed in agriculture and resource occupations. The changes accounting for the majority of the total change are highlighted in bold.

Source: CORTES, JAIMOVICH, and Siu (2017).

Panel B performs a similar analysis with regards to the change in routine cognitive employment between 1989 and 2014. Given that the decline in routine cognitive employment is entirely driven by the propensity effect, we focus only on the groups that are most important in accounting for the changes in this component. The table shows that the groups accounting for the bulk of the decline in routine cognitive propensity are young and prime-aged females with either high school diplomas or some postsecondary education. These groups account for $62 \%$ of the propensity effect.

In Table 6 we document the change in the population share and the change in routine employment propensities for each of these key groups. Panel A focuses on the groups of men with low levels of education that are important in accounting for the decline in routine manual employment. These groups are shrinking in terms of their share of the population (i.e., $w_{g}$ is falling). While they represented nearly a quarter of the U.S. 
population in 1979, they represent less than $15 \%$ in 2014. Individuals from these key groups have also experienced dramatic reductions in the propensity to work in routine manual jobs (i.e., $\pi_{g}$ is falling as well). For example, the fraction has fallen by about 25 percentage points for low-educated young men; while more than $60 \%$ of such individuals worked in a routine manual occupation in 1979, this is closer to one-third in 2014.

\section{TABLE 6 - Key Demographic Groups}

\section{Panel A: Routine Manual}

\begin{tabular}{lccc|ccc} 
& \multicolumn{3}{c}{ Population Share (\%) } & \multicolumn{3}{c}{ Fraction in RM (\%) } \\
\hline & 1979 & 2014 & Change & 1979 & 2014 & Change \\
\hline Male High School Dropouts & & & & & & \\
$\quad$ Age 20-29 & 1.90 & 0.89 & -1.01 & 61.58 & 37.87 & -23.70 \\
Age 30-49 & 4.12 & 2.06 & -2.06 & 63.19 & 48.94 & -14.25 \\
Age 50-64 & 4.68 & 1.51 & -3.17 & 43.09 & 32.92 & -10.17 \\
Male High School Graduates & & & & & & -26.36 \\
$\quad$ Age 20-29 & 6.27 & 3.82 & -2.45 & 61.36 & 34.99 & -10.72 \\
Age 30-49 & 7.51 & 6.60 & -0.91 & 55.11 & 44.39 & \\
\hline
\end{tabular}

\section{Panel B: Routine Cognitive}

\begin{tabular}{lccc|ccc} 
& \multicolumn{3}{c}{ Population Share (\%) } & \multicolumn{3}{c}{ Fraction in RC (\%) } \\
\hline & 1989 & 2014 & Change & 1989 & 2014 & Change \\
\hline Female High School Graduates & & & & & & \\
$\quad$ Age 20-29 & 5.82 & 3.05 & -2.77 & 32.61 & 22.73 & -9.89 \\
$\quad$ Age 30-49 & 10.58 & 5.57 & -5.01 & 32.68 & 23.81 & -8.87 \\
Female with Some College & & & & & & -12.31 \\
$\quad$ Age 20-29 & 3.88 & 4.70 & 0.82 & 36.77 & 24.46 & -7.54 \\
Age 30-49 & 5.48 & 6.32 & 0.84 & 33.04 & 25.50 & \\
\hline
\end{tabular}

Note: The table presents the change in the population share and the propensity to be employed in routine manual and routine cognitive occupations for the key demographic groups identified in Table 5.

Source: CORTES, JAIMOVICH, and Siu (2017).

Panel B documents the analogous patterns for the groups of women with intermediate levels of education that are important in accounting for the decline in routine cognitive employment propensities. All four groups experience obvious declines in their probability of working in routine cognitive jobs, falling from approximately one-third in 1989 to one-quarter in 2014.

Given that these key groups have experienced substantial movement out of routine employment, it is of interest to determine where they have sorted into instead. We illustrate this in Table 7 by presenting the change in the share of each demographic group across labor market states. The results in Panel A indicate that the dramatic decline in the probability of working in routine manual for the key demographic groups is offset primarily by increases in non-employment and, to a smaller extent, increases in nonroutine manual employment. Clearly individuals from these demographic groups have not benefited from the increase in employment in high-paying, non-routine cognitive occupations observed in the aggregate. 
TABLE 7 - Change in the Fraction of Workers in Each Group (p.p.)

\begin{tabular}{|c|c|c|c|c|c|}
\hline \multicolumn{6}{|c|}{ Panel A: Routine Manual, 1979-2014 } \\
\hline & NRC & $\mathbf{R C}$ & $\mathbf{R M}$ & NRM & Not Working \\
\hline \multicolumn{6}{|c|}{ Male High School Dropouts } \\
\hline Age 20-29 & -1.10 & 2.16 & -23.70 & 7.47 & 15.17 \\
\hline Age $30-49$ & -4.95 & 0.62 & -14.25 & 9.02 & 9.55 \\
\hline Age 50-64 & -6.31 & -0.12 & -10.17 & 2.66 & 13.95 \\
\hline \multicolumn{6}{|c|}{ Male High School Graduates } \\
\hline Age 20-29 & -3.81 & 5.22 & -26.36 & 7.79 & 17.16 \\
\hline Age $30-49$ & -8.37 & 0.64 & -10.72 & 5.32 & 13.13 \\
\hline \multicolumn{6}{|c|}{ Panel B: Routine Cognitive, 1989-2014 } \\
\hline & NRC & $\mathbf{R C}$ & $\mathbf{R M}$ & NRM & Not Working \\
\hline \multicolumn{6}{|c|}{ Female High School Graduates } \\
\hline Age $20-29$ & -2.58 & -9.89 & -4.39 & 7.06 & 9.79 \\
\hline Age 30-49 & -2.05 & -8.87 & -3.34 & 6.28 & 7.99 \\
\hline \multicolumn{6}{|c|}{ Female with Some College } \\
\hline Age 20-29 & -4.42 & -12.31 & -1.16 & 9.94 & 7.96 \\
\hline Age $30-49$ & -3.78 & -7.54 & -0.24 & 7.44 & 4.11 \\
\hline
\end{tabular}

Note: The table details the changes in the fraction of workers in each occupational category and not working among the groups identified as accounting for the majority of the decline in routine manual employment and routine cognitive employment propensity. NRC stands for Non-Routine Cognitive, RC for Routine Cognitive, RM for Routine Manual, and NRM for Non-Routine Manual.

Source: CORTES, JAIMOVICH, and SiU (2017).

In Panel B we find that the decline in the probability of working in routine cognitive occupations among the key groups of women with intermediate levels of education has also not been met by an increase in the propensity to work in high-paying, non-routine cognitive occupations. Instead, they have increased their propensities for non-employment and employment in non-routine manual occupations (with the former more prevalent among high school graduates, and the latter among those with some college). Relative to the male groups in Panel A, we generally observe smaller increases in non-employment rates among the female groups that account for the bulk of the decline in routine cognitive propensity.

\section{Aggregate Importance of These Demographic Groups}

How much of the aggregate change in other labor market outcomes can be accounted for by the propensity change of the key demographic groups that account for the bulk of the decline in routine employment? To determine this, we perform some simple counterfactual exercises in Table 8 . The first column reproduces the change in the population share of routine employment, non-routine manual employment, and non-employment, as shown in Column (3) of Table 4. The second column reproduces the propensity effect from Column (5) of Table 4. This represents a counterfactual holding the population shares of all demographic groups constant at their benchmark level (1979 in Panel A, 1989 in Panel B) and allowing all group-specific propensities to change as empirically observed. 
TABLE 8 - Observed and Counterfactual Changes in Population Shares (p.p.)

\begin{tabular}{lcccc}
\hline & $\begin{array}{c}\text { Observed } \\
\text { (1) }\end{array}$ & $\begin{array}{c}\text { Propensity } \\
\text { (2) }\end{array}$ & $\begin{array}{c}\text { Accounting CF } \\
\text { (3) }\end{array}$ & $\begin{array}{c}\text { Mitigating CF } \\
\text { (4) }\end{array}$ \\
\hline Panel A: 1979-2014 & & & & \\
$\quad$ Routine & -9.30 & -7.67 & -6.20 & -5.37 \\
Non-Routine Manual & 3.85 & 6.55 & 4.17 & 0.85 \\
Non-Employment & -1.27 & 4.03 & 3.14 & -2.81 \\
\hline Panel B: 1989-2014 & & & & \\
$\quad$ Routine & -9.37 & -7.90 & -5.68 & -5.36 \\
Non-Routine Manual & 2.71 & 4.68 & 2.81 & 0.57 \\
Non-Employment & 3.14 & 5.88 & 4.21 & 0.24 \\
\hline
\end{tabular}

Note: Column (1) shows the total observed change in the fraction of the population in different labor market categories, based on individuals aged 20-64 from the monthly Current Population Survey, excluding those employed in agriculture and resource occupations. Column (2) shows the counterfactual changes that are obtained when allowing for changes in the propensities to enter different labor market categories among all demographic groups, holding the composition of demographic groups in the population at benchmark levels. Column (3) shows the counterfactual changes (CF) that are obtained when holding the composition of all demographic groups in the population at benchmark levels, and holding the propensities at benchmark levels for all groups except those identified as being key for the decline in routine employment. Column (4) shows the counterfactual changes that are obtained when allowing the composition of demographic groups to change as in the data, while holding the propensities at benchmark levels only for the groups identified as being key for the decline in routine employment.

Source: CORTES, JAIMOVICH, and SIU (2017).

The third column presents the result of a counterfactual in which only the propensities of the key groups are allowed to change; demographic composition and all other propensities are held constant at benchmark levels. This allows us to determine how much of the changes in Columns (1) and (2) are accounted for by the behavioral changes in our key groups. We find that about $65 \%$ of the fall in per capita routine employment is accounted for by the propensity change of our key groups. This confirms the aggregate quantitative importance of the propensity change in the groups that we have identified.

More interestingly, even though the demographic groups were chosen solely based on their importance in accounting for the decline in routine employment, Table 8 shows that the behavioral change of these groups is also important in accounting for the aggregate changes in non-routine manual employment and non-employment. The propensity change of our key groups accounts for more than $100 \%$ of the observed increase in non-routine manual employment, and about $60 \%$ of the overall propensity effect. Moreover, as Panel B indicates, the propensity change of our key groups accounts for more than $100 \%$ of the observed increase in non-employment, and about $70 \%$ of the propensity effect.

In the fourth column we perform a counterfactual in which the demographic composition of the economy is allowed to change as observed in the data, and we also allow all propensities to change, except those of the key groups, which are held constant at benchmark levels. This allows us to assess how much of the observed changes can be mitigated by omitting the behavioral change of our key groups. As indicated in Panel A, if the propensity change of the key groups responsible for the 
decline of routine employment had not occurred, non-routine manual employment would only have risen by 0.85 percentage points. This mitigates $78 \%$ of the observed increase. Similarly, in Panel B, omitting the key demographic groups mitigates $92 \%$ of the observed increase in non-employment.

To summarize, the changes in employment and occupational choice of a small subset of demographic groups account for a large share of the decline in routine employment. These same groups are also key in understanding the rise of nonemployment in the U.S. observed in the past 25 years and, to a slightly lesser extent, the rise of non-routine manual employment observed since 1979. This suggests that these long-run labor market changes are closely linked phenomena.

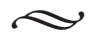

The evidence reviewed in this paper shows that the decline in routine employment has had very heterogeneous effects across different subsets of workers. Using longitudinal data for male workers, in CORTES (2016) I show that routine workers of relatively high ability are more likely to switch to non-routine cognitive jobs, while routine workers of relatively low ability are more likely to switch to non-routine manual ones. I also find that workers staying in routine jobs perform significantly worse in terms of their long-run wage growth than workers who switch to other occupations. In other words, conditional on remaining employed, the workers who are hardest hit in the long run by the effects of technological change are those who stay in routine jobs, not those who switch to other occupations. These findings suggest that it may be a more promising public policy tool to try to retrain workers who are currently in declining routine occupations, rather than trying to help them stay in their current jobs.

The evidence based on repeated cross-sectional data in CORTES, JAIMOVICH, and SIU (2017), meanwhile, highlights the fact that the majority of the decline in routine employment can be traced back to changes among a small subset of demographic groups. Specifically, most of the decline in routine manual employment is driven by changes among men with low levels of education, while most of the decline in routine cognitive employment is driven by changes among women with intermediate levels of education. Routine jobs used to be a major source of employment for workers from these demographic groups, and this has changed dramatically over the past three or four decades. Even though we know that, in aggregate, employment has been growing strongly in high-paying non-routine cognitive jobs, we find that the key demographic groups that we have identified have not benefited from this employment growth. Instead, they have become more likely to work in low-paying non-routine manual jobs, or to be out of work altogether. In fact, we find that a substantial proportion of the increase in non-employment observed in the U.S. since the late 1980s can be traced back to the small set of demographic groups that are key in accounting for the decline in routine employment. 
Overall, the findings illustrate the fact that, as the structure of the labor market changes, there are both winners and losers. Our results can help guide public policy by identifying the segments of the population that have been most negatively impacted by the decline of routine employment. Evaluating specific policies that may help those who are being negatively affected by these changes in the structure of the labor market would be a promising avenue for future research.

\section{REFERENCES}

ACEMoglu, D., Autor, D. (2011). "Chapter 12 - Skills, Tasks and Technologies: Implications for Employment and Earnings." In O. Ashenfelter, D. Card (Eds.), Handbook of Labor Economics, vol. 4, part B (pp. 1043-1171). Elsevier. https://doi.org/10.1016/S0169-7218(11)02410-5.

Albertini, J., Hairault, J.-O., Langot, F., Sopraseuth, T. (2017). A Tale of Two Countries: A Story of the French and US Polarization. IZA Discussion Paper, no 11013, Bonn: IZA, Institute of Labor Economics.

Autor, D. H., Dorn, D. (2013). "The Growth of Low-Skill Service Jobs and the Polarization of the US Labor Market." American Economic Review, 103(5), 1553-1597. https://doi. org/10.1257/aer.103.5.1553.

Autor, D. H, Dorn, D., Hanson, G. H. (2015). "Untangling Trade and Technology: Evidence from Local Labour Markets." The Economic Journal, 125(584), 621-646. https://doi. org/10.1111/ecoj.12245.

Autor, D. H., Levy, F., Murnane, R. J. (2003). “The Skill Content of Recent Technological Change: An Empirical Exploration.” The Quarterly Journal of Economics, 118(4), 1279-1333. https://doi.org/10.1162/003355303322552801.

Böckerman, P., LaAKSONEn, S., VAINIOMÄKI, J. (2019). "Does ICT Usage Erode Routine Occupations at the Firm Level?" Labour, 33(1), 26-47. https://doi.org/10.1111/labr.12137.

Böнм, M. J. (2017). The Price of Polarization: Estimating Task Prices under Routine-Biased Technical Change. IZA Discussion Paper, no 11220, Bonn: IZA, Institute of Labor Economics.

CoRTES, G. M. (2016). "Where Have the Middle-Wage Workers Gone? A Study of Polarization Using Panel Data." Journal of Labor Economics, 34 (1), 63-105. https://doi.org/10.1086/682289.

Cortes, G. M., Gallipoli, G. (2018). "The costs of Occupational Mobility: An Aggregate Analysis." Journal of the European Economic Association, 16(2), 275-315. https://doi. org/10.1093/jeea/jvx006.

Cortes, G. M., Jaimovich, N., Nekarda, C. J., Siu, H. E. (2014). The Micro and Macro of Disappearing Routine Jobs: A Flows Approach. NBER Working Paper, no 20307.

Cortes, G. M., Jaimovich, N., Siu, H. E. (2017). "Disappearing Routine Jobs: Who, How, and Why?" Journal of Monetary Economics, vol. 91, 69-87. https://doi.org/10.1016/j. jmoneco.2017.09.006. 
Cortes, G. M., Salvatori, A. (2019). "Delving into the Demand Side: Changes in Workplace Specialization and Job Polarization.” Labour Economics, 57, 164-176. https://doi.org/10.1016/j. labeco.2019.02.004.

DAUTH, W. (2014). Job Polarization on Local Labor Markets. IAB Discussion Paper, no 18/2014, Nuremberg: IAB, Institute for Employment Research of the Federal Employment Agency.

Dustmann, C., Ludsteck, J., Schönberg, U. (2009). "Revisiting the German Wage Structure." The Quarterly Journal of Economics, 124(2), 843-881. https://doi.org/10.1162/ qjec.2009.124.2.843.

Flood, S., King, M., Ruggles, S., Warren, J. R. (2015). Integrated Public Use Microdata Series, Current Population Survey: Version 4.0. [Machine-readable database]. Minneapolis: University of Minnesota.

Gathmann, C., Schönberg, U. (2010). "How General is Human Capital? A Task-Based Approach.” Journal of Labor Economics, 28(1), 1-49. https://doi.org/10.1086/649786.

Gibbons, R., Katz, L. F., Lemieux, T., PArent, D. (2005). “Comparative Advantage, Learning, and Sectoral Wage Determination.” Journal of Labor Economics, 23(4), 681-724. https://doi. org/10.1086/491606.

Goos, M., Manning, A. (2007). "Lousy and Lovely Jobs: The Rising Polarization of Work in Britain.” The Review of Economics and Statistics, 89(1), 118-133. https://doi.org/10.1162/ rest.89.1.118.

Goos, M., Manning, A., Salomons, A. (2009). "Job Polarization in Europe." American Economic Review, 99(2), 58-63. http://doi.org/10.1257/aer.99.2.58.

Goos, M., Manning, A., SAlomons, A. (2014). "Explaining Job Polarization: Routine-Biased Technological Change and Offshoring." American Economic Review, 104(8), 2509-2526. https://doi.org/10.1257/aer.104.8.2509.

Goos, M., Rademakers, E., Salomons, A., Vandeweyer, M. (2019, forthcoming). "Job Polarization: Its History, An Intuitive Framework and Some Empirical Evidence.” In C. Warhust (Ed.), Oxford Handbook of Job Quality. Oxford: Oxford University Press.

GotTschalk, P., Green, D. A., SAnd, B. M. (2015). Taking Selection to Task: Bounds on Trends in Occupational Task Prices for the U.S., 1984-2013. Working Paper.

Groes, F., Kircher, P., Manovskit, I. (2015). "The U-Shapes of Occupational Mobility.” The Review of Economic Studies, 82(2), 659-692. https://doi.org/10.1093/restud/rdu037.

Harrigan, J., Reshef, A., Toubal, F. (2016). The March of the Techies: Technology, Trade, and Job Polarization in France, 1994-2007. NBER Working Paper, no 22110.

Heyman, F. (2016). "Job Polarization, Job Tasks and the Role of Firms." Economics Letters, 145, 246-251. https://doi.org/10.1016/j.econlet.2016.06.032.

Jaimovich, N., Siu, H. E. (2012). The Trend is the Cycle: Job Polarization and Jobless Recoveries. NBER Working Paper, no 18334. 
Kambourov, G., ManovskiI, I. (2008). "Rising Occupational and Industry Mobility in the United States: 1968-97." International Economic Review, 49(1), 41-79. https://doi. org/10.1111/j.1468-2354.2008.00473.x.

KAMBourov, G., MANOvSKII,I. (2009). “Occupational Specificity of Human Capital.” International Economic Review, 50(1), 63-115. https://doi.org/10.1111/j.1468-2354.2008.00524.x.

King, M., Ruggles, S., Alexander, J. T., Flood, S., Genadek, K., Schroeder, M. B., Trampe, B., Vick, R. (2010). Integrated Public Use Microdata Series, Current Population Survey: Version 3.0. [Machine-readable database]. Minneapolis: University of Minnesota.

Moscarini, G., Thomsson, K.(2007). “Occupational and JobMobility in the US.”'The Scandinavian Journal of Economics, 109(4), 807-836. https://doi.org/10.1111/j.1467-9442.2007.00510.x.

National Academy of Science, Committee on Occupational Classification and Analysis (1977, 1981). Dictionary of Occupational Titles (DOT): Part I - Current Population Survey, April 1971, Augmented with DOT Characteristics, and Part II - Fourth Edition Dictionary of DOT Scores for 1970 Census Categories [Computer File]. National Academy of Sciences Committee on Occupational Classification and Analysis, Washington DC: U.S. Department of Commerce, Bureau of the Census [Producer], 1977. Ann Arbor, MI: Inter-university Consortium for Political and Social Research [Distributor], 1981.

Pekkala Kerr, S., Maczulskij, T., Maliranta, M. (2016). Within and Between Firm Trends in Job Polarization: Role of Globalization and Technology. Working Papers, no 308, Helsinki: Labour Institute for Economic Research.

Poletaev, M., Robinson, C. (2008). "Human Capital Specificity: Evidence from the Dictionary of Occupational Titles and Displaced Worker Surveys, 1984-2000.” Journal of Labor Economics, 26(3), 387-420. https://doi.org/10.1086/588180.

Sullivan, P. (2010). "Empirical Evidence on Occupation and Industry Specific Human Capital." Labour Economics, 17(3), 567-580. https://doi.org/10.1016/j.labeco.2009.11.003. 